\title{
Contraceptive Use in India: A Data Mining Approach
}

\author{
Aalok Ranjan Chaurasia \\ Shyam Institute, Bhopal, Madhya Pradesh 462003, India \\ Correspondence should be addressed to Aalok Ranjan Chaurasia; aranjan@shyaminstitute.in
}

Received 17 March 2014; Accepted 6 July 2014; Published 3 August 2014

Academic Editor: Jonathan Haughton

Copyright (C) 2014 Aalok Ranjan Chaurasia. This is an open access article distributed under the Creative Commons Attribution License, which permits unrestricted use, distribution, and reproduction in any medium, provided the original work is properly cited.

\begin{abstract}
This paper uses data mining approach to analyse patterns of contraceptive use in India by comparing contraceptive use among groups of women with distinct demographic, economic, cultural, and social characteristics. The analysis suggests that currently married, nonpregnant women aged 15-49 years in India can be classified into 13 mutually exclusive groups on the basis of six characteristics of women-surviving children, household standard of living, religion, women's years of schooling, husbands' education, and residence. Contraceptive use pattern in these 13 groups is essentially different and reflects the orientation of family planning efforts, especially, official family planning efforts in the country. The observed differences in the patterns of contraceptive use have important policy and programme implications in the context of universal access to family planning.
\end{abstract}

\section{Introduction}

Contraception is one of the proximate determinants of fertility and the most important predictor of fertility transition $[1,2]$. The choice of the contraceptive method, however, is influenced by a host of interdependent demographic, cultural, economic, and social factors which means that a multidimensional approach needs to be adopted for analysing the contraceptive use pattern. Any analysis based on a single indicator is unlikely to capture all the dimensions of contraceptive method choice.

Contraceptive use can be characterised in terms of both prevalence of different contraceptive methods and specific characteristics of acceptors which differentially influence use of different contraceptive methods. The challenge is how to classify contraceptive use pattern on the basis of a selected set of characteristics of acceptors. Identification of similarities and dissimilarities in the acceptors of different contraceptive methods is important in understanding contraceptive use dynamics.

India was the first country in the world to adopt an official population policy and launch official family planning programme way back in 1952 which remains the mainstay of family planning efforts. During its early years, the programme focussed on the health rationale of family planning. Family planning as a strategy for population stabilisation received attention only after 1971 population census [3]. This strategy resulted in an increase in the proportion of couples effectively protected from 12.4 percent during 1971-72 to 46.5 percent during $1995-96$ but remained stagnant during 1995-96 through 2003-04 and decreased to 40.4 during 201011. After the launch of the National Rural Health Mission in 2005, the official family planning programme has been subsumed in the reproductive and child health component of the Mission [4]. However, universal adoption of small family norm still remains a distant dream in India. During 200708 , only about 54 percent of the currently married women aged 15-49 years or their husbands were using a contraceptive method to regulate their fertility [5] and the contraceptive prevalence rate appears to have stagnated after 2004 [6]. Moreover, contraceptive practice in India is known to be very heavily skewed towards terminal methods which means that contraception in India is practised primarily for birth limitation rather than birth planning.

In this paper, we analyse the pattern of contraceptive use in India through data mining approach. By pattern of contraceptive use, we mean both prevalence of different contraceptive methods and contraceptive method mix. Data mining is essentially the process of discovering knowledge from data [7]. There is a large number of methods that are available for the purpose $[8,9]$. Some of these have 
grounding in statistics, while others have stemmed from artificial intelligence. One of the data mining approaches is decision tree which is intuitively more appealing than other model-based classification approaches such as logistic regression. Popular decision tree algorithms include CART and CHAID. CART (Classification and regression tree) is a nonparametric technique that can select from a large number of variables those variables and their interaction that are most important in determining the outcome variable to be explained [10]. We apply CART decision tree algorithm to identify women with distinct social, economic, cultural, and demographic characteristics who have different contraceptive use pattern and then analyse how the pattern of contraceptive use varies across these groups.

The paper is organised as follows. Section 2 describes the data used in the analysis. Section 3 outlines the method while Section 4 presents the classification tree of contraceptive use. Section 5 presents a comparative analysis of the pattern of contraceptive use in different groups of women identified through the application of CART algorithm. Policy and programme implications of contraceptive use pattern are discussed in Section 6. Section 7 summarises findings of the analysis and draws main conclusions.

\section{The Data}

Data for the present analysis are derived from the district level household and facility survey (DLHS) 2007-08 which covered more than 720 thousand households in all districts of 28 states and 6 union territories of the country as they existed at the time of the survey [5]. The survey could not be carried out in Nagaland. During the survey, information related to contraceptive use by the woman or her husband was collected along with their selected social, economic, cultural, and demographic characteristics from more than 604 thousand currently married women aged $15-49$ years.

The present analysis is based on the information related to 555,665 currently married women aged $15-49$ years who were either not pregnant or not sure about their pregnancy status at the time of the survey. About 8 percent or 49,139 of currently married women reported at the time of the survey that they were pregnant and so were excluded from the analysis. For the present analysis, contraceptive methods were grouped into three categories-terminal methods (female and male sterilisation), modern spacing methods (intrauterine device, daily or weekly pill, female or male condom, and injectable), and traditional methods (rhythm, withdrawal, and all other methods). The pattern of contraceptive use has been analysed in terms of six characteristics of women-number of surviving children $(0,1,2-3$, and $>3$ ), religion (Hindu, Muslim, and others), residence (rural and urban), number of years of schooling of the woman and her husband (1-8 years, 912 years, and $>12$ years), and household standard of living (very low, low, average, high, and very high). The living standard of the household was determined on the basis of the household wealth index which has been estimated on the basis of household level assets, amenities, and durables available at the time of the survey. The standard of living of a household was categorised as very low if the wealth index of the household was less than the lowest wealth quintiles. The standard of living of a household was categorised as very high if the household wealth index was more than the highest wealth quintiles [5]. Similarly, the standard of living of a household was categorised as low if the wealth index of the household was more than the lowest wealth quintiles but less than the second wealth quintiles; average if the wealth index of the household was more than the second wealth quintiles but less than the third wealth quintiles; and high if the wealth index of the household was more than the third wealth quintiles but less than the fourth wealth quintiles.

Table 1 gives the distribution of currently married, nonpregnant women aged 15-49 years surveyed during DLHS 2007-08 by selected demographic, economic, cultural, and social characteristics. About 8 percent of the women surveyed had no surviving child, while about 15 percent of women had one surviving child. About one-fourth of the women surveyed had two surviving children and almost half of them had more than two surviving children. Majority of the women were residing in rural areas and were Hindu by religion. Around 47 percent of them had no schooling, while less than 5 percent had more than 12 years of schooling. By contrast, husbands of about one-fourth women had no schooling, while one in every ten had more than 12 years of schooling. On the other hand, around 16 percent of women belonged to households with very low standard of living; 19 percent belonged to households with low standard of living; 20 percent belonged to households with average standard of living; 21 percent belonged to households with high standard of living; and almost 23 percent belonged to households with very high standard of living.

Table 1 also presents prevalence of contraception among women included in this analysis. About 58 percent of the currently married, nonpregnant women, aged 15-49 years in India, were using some contraceptive methods at the time of DLHS 2007-08 with significant variation across different demographic, economic, cultural, and social characteristics of women. Contraceptive use ranged from just about 8 percent among women having no surviving child to more than 68 percent among women with at least two surviving children. There appears a direct relationship between the prevalence of contraception and standard of living of the household and schooling of women and their husbands. The prevalence of contraception is found to be the highest among women belonging to households with very good standard of living and among women with more than 12 years of schooling but lowest among women belonging to households with very low standard of living and among women who had never been to the school. Contraceptive use has also been found to be relatively high among urban as compared to rural women. Across different religions, contraceptive prevalence has been found to be the lowest among Muslim women but the highest among Hindu women. Among women of other religions, contraceptive prevalence has been found to be very close to that among Hindu women.

The highly skewed contraceptive method mix in India is reflected from the fact that almost 68 percent of contraceptive users in the country had adopted terminal methods 
TABLE 1: Prevalence of contraception in currently married, nonpregnant women aged 15-49 years in India.

\begin{tabular}{|c|c|c|c|c|c|}
\hline \multirow{2}{*}{ Particulars } & \multirow{2}{*}{$\begin{array}{c}\text { Proportion of } \\
\text { women (percent) }\end{array}$} & \multicolumn{4}{|c|}{ Prevalence (percent) } \\
\hline & & All methods & Terminal methods & Modern spacing methods & Traditional methods \\
\hline \multicolumn{6}{|l|}{ Locality } \\
\hline Rural & 78.0 & 56.4 & 39.6 & 9.5 & 7.2 \\
\hline Urban & 22.1 & 65.3 & 39.6 & 18.0 & 7.6 \\
\hline \multicolumn{6}{|l|}{ Standard of living } \\
\hline Very low & 16.5 & 43.8 & 31.8 & 5.1 & 6.9 \\
\hline Low & 18.5 & 51.1 & 37.7 & 6.4 & 7.0 \\
\hline Average & 20.4 & 59.3 & 43.4 & 9.0 & 7.0 \\
\hline High & 21.8 & 64.3 & 44.7 & 12.4 & 7.2 \\
\hline Very high & 22.8 & 68.1 & 38.6 & 21.3 & 8.3 \\
\hline \multicolumn{6}{|l|}{ Wife education } \\
\hline No schooling & 46.7 & 54.7 & 42.6 & 5.9 & 6.2 \\
\hline Upper primary & 30.2 & 61.4 & 42.4 & 11.8 & 7.2 \\
\hline Higher Secondary & 18.4 & 61.2 & 32.4 & 19.4 & 9.4 \\
\hline College & 4.9 & 63.7 & 21.2 & 31.6 & 11.0 \\
\hline \multicolumn{6}{|l|}{ Husband education } \\
\hline No schooling & 24.8 & 53.2 & 41.5 & 5.7 & 6.0 \\
\hline Upper primary & 34.2 & 59.1 & 42.9 & 9.4 & 6.8 \\
\hline Higher Secondary & 30.9 & 60.0 & 37.5 & 14.4 & 8.1 \\
\hline College & 10.2 & 63.4 & 31.0 & 22.6 & 9.8 \\
\hline \multicolumn{6}{|l|}{ Religion } \\
\hline Hindu & 78.0 & 59.9 & 43.0 & 10.0 & 6.9 \\
\hline Muslim & 11.3 & 46.7 & 21.0 & 15.1 & 10.6 \\
\hline Others & 10.7 & 59.5 & 34.8 & 17.7 & 7.0 \\
\hline \multicolumn{6}{|l|}{ Surviving children } \\
\hline 0 & 8.5 & 8.2 & 0.7 & 4.2 & 3.3 \\
\hline 1 & 14.9 & 35.9 & 6.3 & 19.3 & 10.2 \\
\hline 2 & 27.4 & 69.2 & 46.5 & 15.2 & 7.5 \\
\hline$>2$ & 36.4 & 62.2 & 47.3 & 7.2 & 7.7 \\
\hline Total & 100.0 & 58.3 & 39.6 & 11.4 & 7.3 \\
\hline$N$ & 555665 & & & & \\
\hline
\end{tabular}

of contraception, while only about one-fifth were using a modern spacing method. Users of traditional methods, on the other hand, accounted for around 12 percent of the total contraceptive users in the country. The contraceptive method mix is heavily skewed towards terminal methods among rural women; among women belonging to poorest, poor, and middle income households; and among Hindu women. On the other hand, at least half of the contraceptive users having at least 12 years of schooling were using a modern spacing method. Similarly, more than half of the users having either no or one surviving child were using a modern spacing method, while around 40 percent were using a traditional method.

\section{The Method}

The method adopted in the present analysis first classifies currently married, nonpregnant women aged 15-49 years into different groups with distinct demographic, economic, cultural, and social characteristics and then analyses contraceptive use pattern in each group separately. The approach is different from the regression-based approach that is commonly used for analysing marginal effects of characteristics of women on contraceptive use [11]. Classification modelling allows exploring varied factors potentially influencing use of different contraceptive methods. There are no restrictions or limitations on the structure of independent variables included in classification modelling.

The classification analysis presented in this paper is based on the application of classification and regression tree (CART) algorithm [12]. It is a nonparametric technique that divides the entire population into different subgroups in a manner that maximises within group homogeneity. It is an iterative process that sorts data in terms of the dependent variable into mutually exclusive categories based on the predictor or independent variable that causes the most 
effective split on the basis of a measure of similarity-that variable is selected first for the purpose of classification which produces highest similarity. The process continues till perfect similarity is obtained or stopping rules are met $[13,14]$.

CART produces a classification tree which is turned upside down and built from the root at the top towards leaves at the bottom. Every node in the tree represents a test of some case attributes. A path that leads from root to leaf represents a classification rule that describes associations in the data [14]. The extent to which a group is not a homogenous subset of the population is an indication of impurity of classification. A subgroup in which all cases have the same value for the dependent variable is a homogenous group and is termed as "pure." CART also calculates a measure of impurity in case a class or group of the population is not "pure." There is a number of impurity measures used for the purpose but the most commonly used one is the Gini coefficient which has been used in the present analysis. CART produces very large disaggregation of the original population and, to simplify the results, it prunes the large classification tree through cross validation, thereby avoiding overfitting. The process also produces a cross-validation error rate from which the optimal tree is selected.

CART has a number of advantages as an exploratory data analysis procedure. It makes no assumption about the distribution of dependent or independent variables. Application of CART does not assume any kind of statistical distribution of the variables included in the analysis. Moreover, explanatory variables in CART can be a mix of categorical, interval, and continuous variables which makes the approach very versatile. Another advantage of CART is that results of the analysis are not at all affected by outliers, colinearity, heteroscedasticity, or distributional error structures that normally affect parametric procedures.

\section{The Classification Tree}

We have used the CRT subroutine of the Tree procedure in SPSS software in the present analysis. The dependent variable was "use of a contraceptive method" which was categorised as no use (0), terminal methods (1), modern spacing methods (2), and traditional methods (3). The independent variables included number of surviving children $(0,1,2$, and $>2)$, household standard of living (very low, low, average, high, and very high), religion (Hindu, Muslim, and others), years of schooling of the women and their husbands $(0,1-8,9-12$, and $>12$ ), and residence (rural and urban). Prevalence of different contraceptive methods and contraceptive method mix varies widely across these categories as may be seen from Table 1.

The classification table generated through the application of CRT subroutine is given in Table 2. The first split of 555,665 currently married, nonpregnant women aged 1549 years was on the "number of surviving children" which divided women into two groups-women having at least two surviving children (76.7 percent) and women having either no or one surviving child (23.3 percent). Contraceptive prevalence in the two groups was around 26 percent and more than 68 percent, respectively.
At the second level, women having either no or one surviving child were split again on the "number of surviving children" into women having one surviving child (14.8 percent) and women having no surviving child ( 8.5 percent). Contraceptive prevalence in the first group was 36 percent compared to 8 percent in the second group. On the other hand, women having at least two surviving children were split on "religion" into Muslim women ( 8.9 percent) and women belonging to Hindu and other religions (67.8 percent). Contraceptive prevalence in the first group was around 53 percent compared to more than 70 percent in the second group.

At the third level, Muslim women were split on "household standard of living" into women belonging to households with very low and low standard of living ( 2.7 percent) and women belonging to households with at least average standard of living (6.2 percent). Contraceptive prevalence in the first group was 40 percent compared to almost 59 percent in the second group. There was no further splitting of Muslim women belonging to households with very low and low standard of living as the desired level of purity was achieved. On the other hand, Muslim women belonging to households with at least average standard of living were further split on "women's years of schooling" into women with no schooling (2.9 percent) and women with some schooling irrespective of number of years of schooling (3.3 percent). The contraceptive prevalence in the first group was around 53 percent compared to 65 percent in the second group. Finally, Muslim women with some schooling were further split on "residence" into women residing in the rural areas (1.7 percent) and women residing in the urban areas (1.6 percent). Contraceptive prevalence in the first group was 61.5 percent compared to 67.6 percent in the urban areas.

Like Muslim women with at least two surviving children, Hindu women and women of other religions having at least two surviving children were also split on "household standard of living" into women belonging to households with very low and low standard of living (24.7 percent) and women belonging to households with at least average standard of living (43.1 percent). Contraceptive prevalence in the first group was 58.8 percent compared to 76.7 percent in the second group. Next, Hindu women belonging to households with very low and low standard of living were further split on "religion" into women of other religions ( 2.3 percent) and Hindu women (22.3 percent). The contraceptive prevalence in the first group was 46.6 percent compared to 60 percent in the second group. On the other hand, there was no further splitting of women belonging to households with at least average standard of living. Finally, Hindu women were split on "household standard of living" into women belonging to households with low standard of living (11.8 percent) and women belonging to households with very low standard of living (10.5 percent). The contraceptive prevalence in the first group was 64.1 percent compared to 55.4 percent in the second group. Further splitting of women from other religions was not possible.

Similarly, women with one surviving child were split on "household standard of living" into women belonging to households with very low, low, and average standard of living (7.2 percent) and women belonging to households with high 


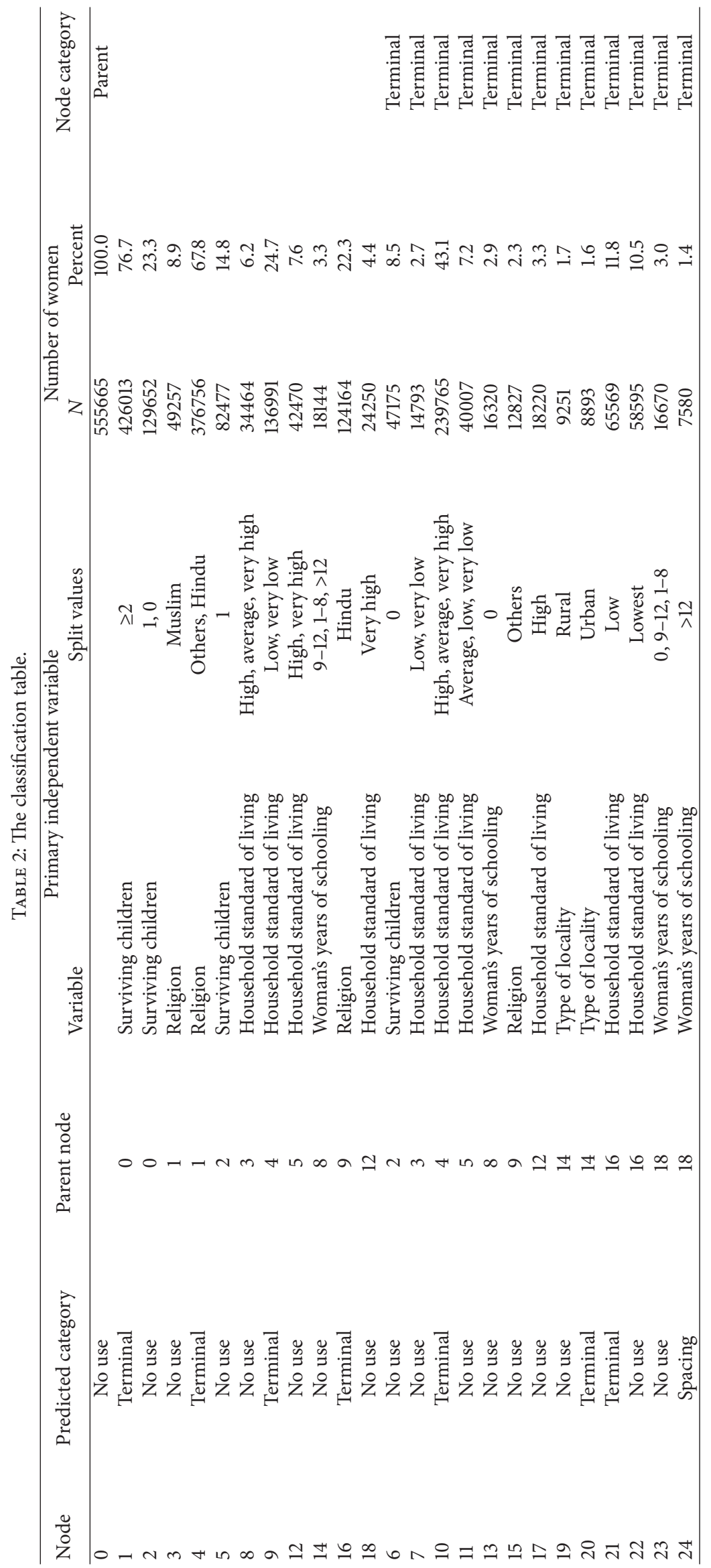


and very high standard of living (7.6 percent). Contraceptive prevalence in the first group was 24.6 percent compared to 46.5 percent in the second group. Further splitting of women with one surviving child and belonging to households with very low, low, and average standard of living was not possible as the desired level of purity in the group was achieved.

On the other hand, women belonging to households with high and very high standard of living were further split on "household standard of living" into women belonging to households with high standard of living (3.3 percent) and women belonging to households with very high standard of living (4.4 percent). Contraceptive prevalence in the first group was 39.2 percent compared to 51.9 percent in the second group. Finally, women belonging to households with very high standard of living were further split on "women's years of schooling" into women with no schooling or up to 12 years of schooling ( 3 percent) and women with more than 12 years of schooling (1.4 percent). Contraceptive prevalence in the first group was 48.9 percent compared to 58.6 percent in the second group.

The classification tree has 25 nodes. In 16 nodes, the classification variable was "no use" and in 8 nodes "use of terminal methods." In only one node, the classification variable was "use of modern spacing methods." The classification process correctly classified about 63 percent of nonusers and almost 80 percent of users of terminal methods. The overall proportion of correct classification was around 59 percent. The most important characteristic of women influencing the contraceptive use was the number of surviving children, while the least was the residence. Compared to the number of surviving children, importance of husband education was found to be less than 6 percent while that of the residence was less than 2 percent (Table 3). Even the influence of household standard of living, religion, and education of the woman on the contraceptive use was found to be not more than one-fifth of the influence of the number of surviving children on the contraceptive use.

Out of the 25 nodes of the classification tree, 13 are terminal nodes or "leaves." Women in each of these terminal nodes have distinct social, economic, cultural, and demographic characteristics and distinct pattern of contraceptive use. Women representing these nodes also vary in size. Currently married, nonpregnant Hindu women and women of other religions, aged 15-49 years, having at least two surviving children and belonging to households with at least average standard of living constitute the largest group accounting for more than 43 percent of all women included in the analysis. By contrast, currently married, nonpregnant women aged 1549 years, having one surviving child, belonging to households with very high standard of living and having more than 12 years of schooling are the smallest group accounting for just 1.4 percent of all women.

\section{Patterns of Contraceptive Use}

The pattern of contraceptive use differs across 13 mutually exclusive groups of women generated through the classification model with the prevalence of contraception ranging
TABLE 3: Importance of characteristics of women in classifying contraceptive use.

\begin{tabular}{lccc}
\hline SN & Characteristics & $\begin{array}{c}\text { Absolute } \\
\text { improvement }\end{array}$ & $\begin{array}{c}\text { Relative } \\
\text { improvement }\end{array}$ \\
\hline 1 & Surviving children & 0.076 & 100 \\
2 & Household income & 0.014 & 17.8 \\
3 & Religion & 0.01 & 12.9 \\
4 & Woman's years of & 0.008 & 10.4 \\
5 & schooling & & 5.8 \\
6 & Husband's years of & 0.004 & 1.9 \\
\hline
\end{tabular}

from just around 8 percent to almost 77 percent (Table 4). Among women with at least two surviving children, contraceptive prevalence varies by standard of living of the household, by religion and, in some categories, by women's years of schooling and residence. Among women with one surviving child, contraceptive prevalence varies by household standard of living and, in one category, by women's years of schooling but not by religion or residence or husband's years of schooling. On the other hand, contraceptive use among women with no surviving child is invariant of any of the six characteristics of women. Similarly, prevalence of terminal, modern spacing, and traditional methods of contraception also varies across 13 groups of women. The intergroup variability in the contraceptive prevalence is the largest in case of terminal methods but smallest in case of traditional methods. In case of modern spacing methods of contraception, the intergroup variability is found to be very similar to that in case of terminal methods.

The contraceptive method mix also varies across the 13 groups of women identified through classification modelling which suggests that preferences and choices of the 13 groups of women as regards use of contraception vary widely (see Table 5). At least 80 percent of Hindu women, having at least two surviving children and belonging to households with low and very low standard of living, were using a terminal method of contraception compared to only about 5 percent of Hindu women belonging to households with very high standard of living and having one surviving child. Similarly, more than 70 percent of women belonging to households with very high standard of living, having one surviving child and more than 12 years of schooling, were using a modern spacing method of contraception compared to only about 8 percent of Hindu women belonging to households with low and very low standard of living and having at least two surviving children. On the other hand, almost 40 percent of women having no surviving child were using a traditional method of contraception compared to only 9 percent of nonMuslim women, having at least two surviving children and belonging to households with at least average standard of living.

It is also obvious from the analysis that the distribution of contraceptive users across 13 mutually exclusive groups is highly unequal. This inequality is the result of both 


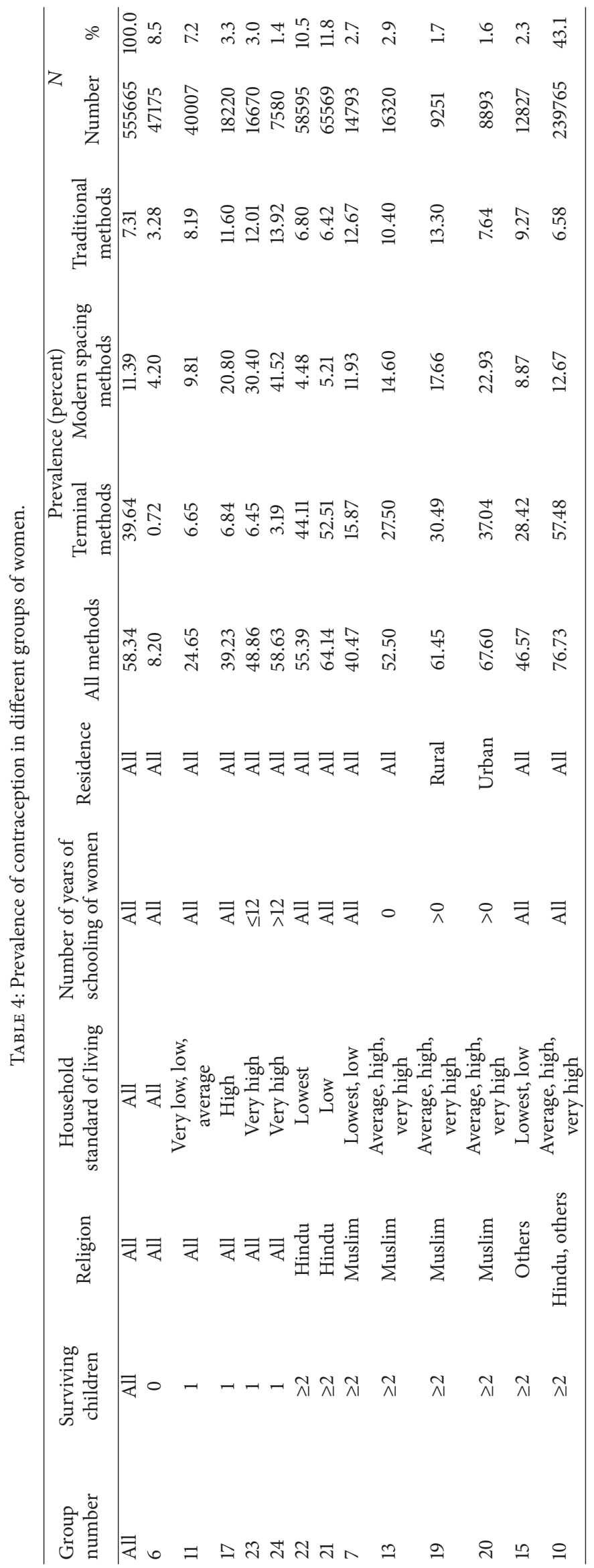




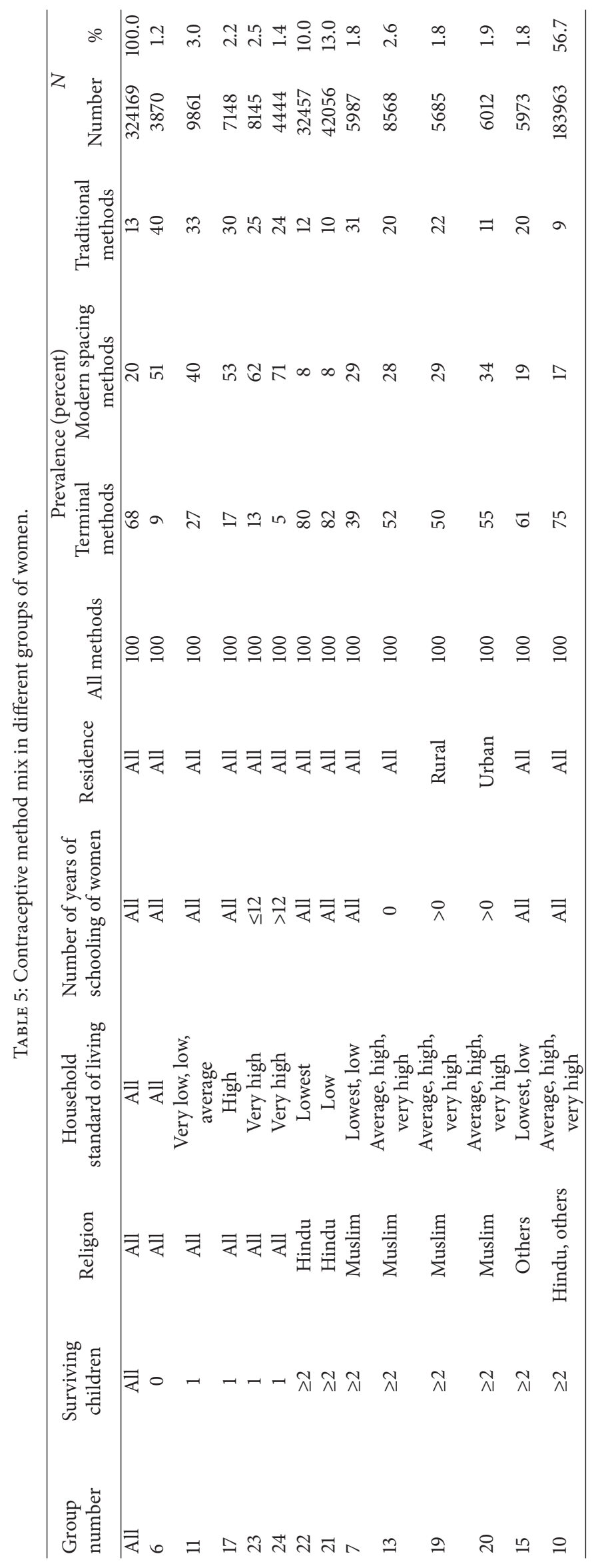




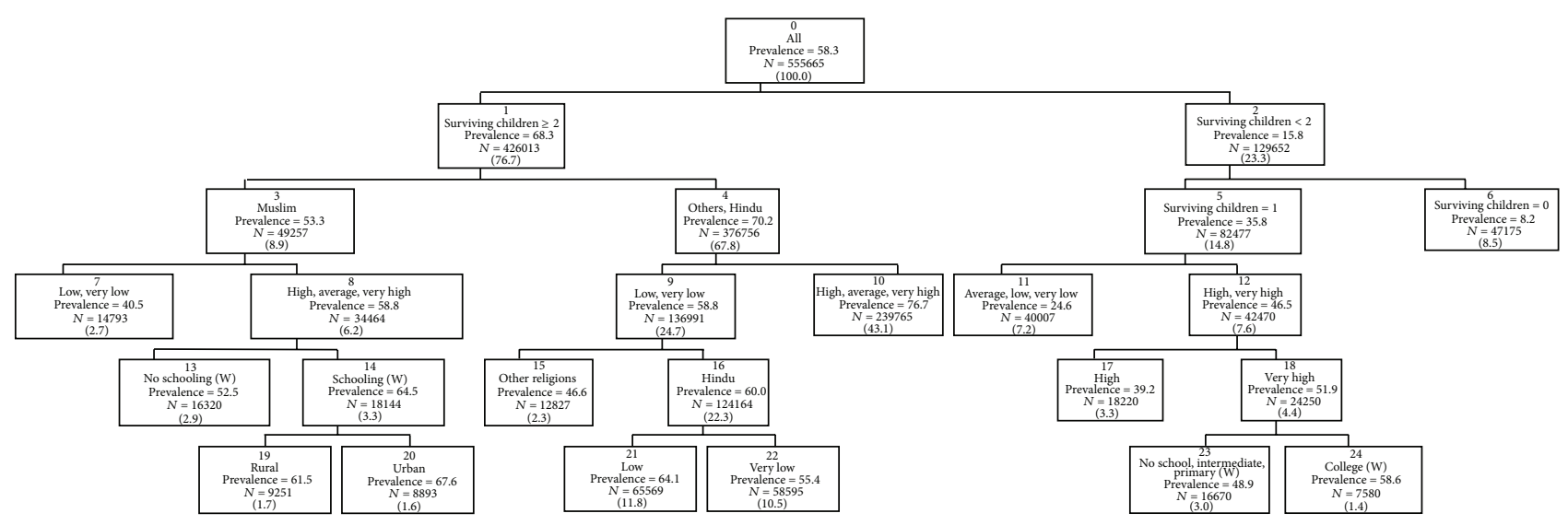

FIGURE 1: The classification tree. Remarks-Figures in the brackets denote the proportion of currently married nonpregnant women aged $15-49$ years.

size of the group and the pattern of contraceptive use in each group. For example, women with no surviving child account for more than 8 percent of all women included in the analysis but only about 1 percent of all contraceptive users. Similarly, women with one surviving child account for around 15 percent of all women but just 9 percent of all contraceptive users. By contrast, women with at least two surviving children account for 77 percent of all women but almost 90 percent of all contraceptive users. In case of terminal methods of contraception, this proportion is more than 97 percent but only 72 percent in case of modern spacing methods and 75 percent in case of traditional methods. Similarly, inequality in contraceptive users across households with different standard of living and religious groups is also evident from the analysis.

\section{Discussion}

The classification model presented in Figure 1 reflects the demand side concerns and supply side constraints of contraceptive use in India. The demand side concerns are reflected in terms of low to very low prevalence of contraception among women who are in the early stages of their reproductive life-women who are in the process of building their family. Low to very low contraceptive prevalence among women having either no or one surviving child may be due to a host of factors which can be grouped into three broad categories: (1) desire to plan the family or, more specifically, desire to postpone the pregnancy, (2) willingness to translate the desire into concrete action, and (3) ability of women to actually act. There may be a situation where women may be having latent desire to postpone the pregnancy but they may not have the will necessary for translating the latent desire into specific action. On the other hand, women may be willing to postpone the pregnancy but they may be constrained by a range of social, cultural, and supply side factors to take specific action that actually leads to postponement of the pregnancy. For example, newly married women may be willing to postpone their first pregnancy but they may be constrained to take specific action because of the family and social pressure to prove their fertility. Similarly, women having one surviving child may be willing to postpone their next pregnancy by using a modern contraceptive method but they may be constrained by no or irregular supply of the method. Although the evidence is sparse, yet low to very low prevalence of contraception among women having no or one surviving child in India has been attributed more to such factors as lack of knowledge and a range of social and cultural factors but less to factors related to the supply of modern spacing methods of contraception. The very fact that 40 percent of the contraceptive users with no surviving child were relying upon traditional methods of contraception to meet their family planning needs substantiates this observation.

A recent study carried out in five states of the country has however revealed that there is substantial demand for contraception among young married women to postpone their first pregnancy but only a small proportion of these women use any contraception [15]. It appears that young married women who are in the process of their family building do not have either the resolve to go for contraception to postpone the pregnancy or their resolve is road-blocked by supply side factors. It is however not clear how much of the unmet need of contraception among young married women is due to the lack of resolve to practice contraception and how much of the unmet need is due to supply side factors.

The pattern of contraceptive use has been found to be highly sensitive to household standard of living irrespective of the number of surviving children and religion. The richpoor gap in contraceptive use is large because of the rich-poor gap in the use of modern spacing methods which is more than four times higher in women belonging to households with very high standard of living as compared to women belonging to households with very low standard of living. The very substantial rich-poor gap in the prevalence of modern spacing methods of contraception reflects the fact that access of women to modern spacing methods of contraception increases with the increase in the household standard of living. At the same time, it may also be argued that women belonging to households with low to very low standard of living may be more interested in producing the desired number 
of children quickly and then go for a terminal method to stop childbearing altogether simply because they may not have the capacity to plan or space the family either because of the lack of knowledge or because of family and society pressure or because of the inability of the family planning services delivery system to ensure regular, uninterrupted supply of modern spacing methods to these women. Obviously, any effort to encourage women belonging to households with low standard of living to space births must be associated with an efficient family planning services delivery system. If the efficiency of the system is poor, any effort to embrace women to space births may largely remain nonproductive. In this context, the present analysis reflects poor efficiency of the family planning services delivery system in the country to ensure supply of modern spacing methods of contraception especially to women belonging to households with low to very low standard of living.

The analysis, surprisingly, reveals limited influence of schooling of women and their husbands on contraceptive use. Similarly, the influence of residence has also been found to be confined to educated Muslim women belonging to households with high to very high standard of living. The reason is that personal characteristics of women are highly correlated with household standard of living. In fact, religion and household standard of living dominate the pattern of contraceptive use. The effect of religion is limited to women with at least two surviving children, whereas household standard of living influences all women except women with no surviving child.

Among Hindu women and women of other religions belonging to households with at least average standard of living, the prevalence of contraception is found to be the highest among all women groups identified in the present analysis. More than two-third of these women are practising contraception and, among the users, three-fourth have adopted terminal methods of contraception to stop childbearing. These women also constitute the largest group accounting for more than 43 percent of all currently married, nonpregnant women aged 15-49 years. Because of its sheer size, the pattern of contraceptive use in this group largely determines the pattern of contraceptive use in the country as a whole. The contraceptive use pattern in this group of women is dominated by terminal methods of contraception. Very high contraceptive prevalence among women belonging to this group suggests that the family planning services delivery system is able to meet most of the family planning needs of these women. Since all women in this group have at least two surviving children, family planning needs of these women may be assumed to be primarily related to birth limitation. This means that the family planning services delivery system in the country is relatively more effective in meeting birth limitation needs of women rather than birth spacing needs.

There appears some type of stigma against terminal methods of contraception among Muslim women irrespective of their education, place of residence, and household standard of living. Although aversion to terminal methods of contraception appears to decrease with the increase in the household standard of living and women's education, yet it clearly persists in Muslim women. By contrast, prevalence of both modern spacing methods and traditional methods is comparatively more among Muslim women belonging to households with at least average standard of living as compared to their Hindu counterparts. The stigma against terminal methods of contraception is also apparent among women of other religions belonging to households with low to very low standard of living.

On the whole, there are only four groups of currently married nonpregnant women aged 15-49 years where the contraceptive prevalence is found to be more than 60 percent although these four groups account for 58 percent of all currently married, nonpregnant women aged 15-49 years. All these women have at least two surviving children and they belong to households with at least average standard of living irrespective of their religion. The only other group of women with a contraceptive prevalence of more than 60 percent is Hindu women belonging to households with low standard of living. Similarly, household standard of living matters most in women having one surviving child as far as contraceptive use is concerned. The contraceptive prevalence among women with one surviving child and belonging to households with average or below average standard of living is less than 25 percent. About one-third of this prevalence is accounted by the use of relatively inefficient traditional methods of contraception.

\section{Conclusions}

The conventional approach of analysing determinants of contraceptive use has been exploring the effect of a given characteristic of women on the use of different contraceptive methods using a number of statistical procedures, the most common of which is the logistic regression on the basis of individual level data [16-19]. In this paper, we have compared contraceptive use among groups of women with distinct demographic, economic, cultural, and social characteristics. The analysis reveals that currently married, nonpregnant women aged 15-49 years in the country can be classified into 13 mutually exclusive groups, each having distinct contraceptive use pattern. These differences in the contraceptive use pattern have important programmatic implementations particularly in the context of universal access to family planning and universal adoption of small family norm. There is a great divide in the pattern of contraceptive use among women with no surviving child, women with one surviving child, and women with at least two surviving children. Similarly, contraceptive use pattern varies by household standard of living and religion of the household. These variations in contraceptive use pattern across different groups of women reflect the skewed demand for and restricted supply of family planning services. Contraceptive prevalence is very low among women with no surviving child and low among women with one surviving child but is quite substantial among women with at least two surviving children. This contraceptive use pattern suggests that the dominating perception across currently married nonpregnant women in India is to produce the desired number of children quickly 
with little spacing between successive births and then opt for terminal methods of contraception to stop childbearing.

The genesis of the skewed demand for contraception and restricted contraceptive supply essentially lies in India's official family planning programme which had been the mainstay of family planning efforts in the country. Right since its inception in 1952, the programme has focused on birth limitation rather than birth planning. The programme preoccupation with birth limitation also appears to be an important factor in its inability to engage young married women-women in the process of building their familyand enable them to realise their family planning intentions. It has also resulted in highly skewed contraceptive method mix and Hindu-Muslim divide in the contraceptive use pattern. This approach of meeting the family planning needs of women appears to be reaching its limit. Future increases in contraceptive prevalence in India will be contingent upon meeting family planning needs of young married women who are in the process of building their family and not the family planning needs of women who have completed their family building process. Recent studies suggest that the demand for family planning in these women is quite substantial. Family planning services delivery system must meet this demand.

From the policy and programme perspective, the findings of the analysis are significant. In the context of universal access to family planning services, there is a need to enhance the needs effectiveness and increase the capacity efficiency of organised family planning efforts so that these efforts can address specific family planning needs of women with distinct social, economic, and personal characteristics as revealed in the present analysis. The reach of family planning efforts in the country is quite substantial but this reach is virtually confined to specific groups of women. The present analysis suggests that contraceptive preferences of different groups of women are quite different. Very little is known at present about the reasons behind differing contraceptive preferences and choices of different groups of women. It is the need of the time that family planning efforts in India explore the determinants of different contraceptive preferences and choices across different women groups and reinvigorate themselves to address these preferences and choices in an efficient yet cost effective manner.

\section{Conflict of Interests}

There is no conflict of interests regarding the publication of this paper.

\section{References}

[1] K. Davis and J. Blake, "Social structure and fertility: an analytical framework," Economic and Cultural Change, vol. 4, pp. 211235, 1956.

[2] J. Bongaarts, "A framework for analysing proximate determinants of fertility," Population and Development Review, vol. 4, pp. 105-131, 1978.

[3] A. R. Chaurasia and S. C. Gulati, India: The State of Population 2007, Government of India, National Population Commission and Oxford University Press, New Delhi, India, 2008.
[4] A. R. Chaurasia and R. Singh, "Forty years of planned family planning efforts in India," in Proceedings of the 2013 IUSSP International Population Conference, Bussan, Republic of Korea, 2013.

[5] International Institute for Population Sciences, District Level Household and Facility Survey (DLHS-3), 2007-08, IIPS, Mumbai, India, 2010.

[6] United Nations, Update for the MDG Database: Contraceptive Prevalence, Department of Economic and Social Affairs, Population Division, New York, NY, USA, 2012.

[7] R. Mikut and M. Reischl, "Data mining tools," Wiley Interdisciplinary Reviews: Data Mining and Knowledge Discovery, vol. 1, no. 5, pp. 431-443, 2011.

[8] T. Hastie, R. Tibshirani, and J. Friedman, The Elements of Statistical Learning: Data Mining, Inference, and Prediction, Springer, New York, NY, USA, 2008.

[9] A. P. Engelbrecht, Computational Intelligence-An Introduction, John Wiley \& Sons, Chichester, UK, 2007.

[10] W. Y. Loh, "Classification and regression trees," Wiley Interdisciplinary Reviews: Data Mining and Knowledge Discovery, vol. 1, no. 1, pp. 14-23, 2011.

[11] K. Grace, "Contraceptive use and intent in Guatemala," Demographic Research, vol. 23, no. 12, pp. 335-364, 2010.

[12] L. Breiman, J. Friedman, R. A. Olshen, and C. J. Stone, Classification and Regression Trees, Wadsworth, 1984.

[13] N. Ambalavanan, A. Baibergenova, W. A. Carlo, S. Saigal, B. Schmidt, and K. E. Thorpe, "Early prediction of poor outcome in extremely low birth weight infants by classification tree analysis," The Journal of Pediatrics, vol. 148, no. 4, pp. 438.el444.e1, 2006.

[14] S. C. Lemon, J. Roy, M. A. Clark, P. D. Friedmann, and W. Rakowski, "Classification and regression tree analysis in public health: methodological review and comparison with logistic regression," Annals of Behavioral Medicine, vol. 26, no. 3, pp. 172-181, 2003.

[15] S. J. Jejeebhoy, K. G. Santhya, and A. J. F. Zavier, "Demand for contraception to delay first pregnancy among young married women in India," Studies in Family Planning, vol. 45, no. 2, pp. 183-201, 2014.

[16] S. Barman, "Socio-economic and demographic differentials in contraceptive use in Indian states: a study based on NFHS data," Journal of Human Ecology, vol. 42, no. 1, pp. 53-68, 2013.

[17] B. M. Ramesh, S. C. Gulati, and R. Retherford, Contraceptive Use in India: 1992-93, East-West Population Centre, Honolulu, Hawaii, USA, 1996.

[18] E. Chacko, "Women's use of contraception in rural India: a village-level study," Health and Place, vol. 7, no. 3, pp. 197-208, 2001.

[19] S. Sarkar, "Contraceptive use and methods choice among currently married women in India," in India 2012: Population, Reproductive and Child Health, A. Ranjan and R. Singh, Eds., MLC Foundation and Shyam Institute, Bhopal, India, 2012. 

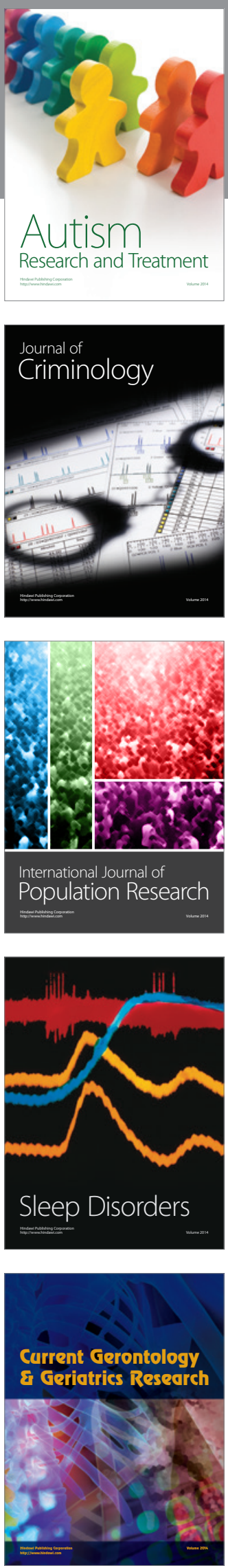
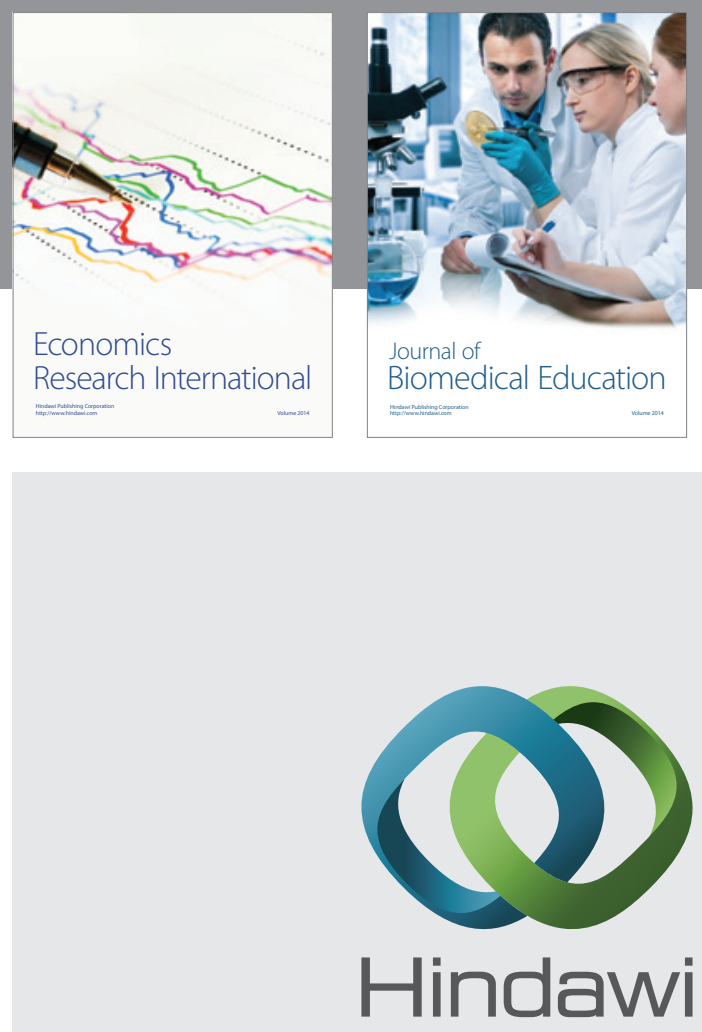

Submit your manuscripts at

http://www.hindawi.com
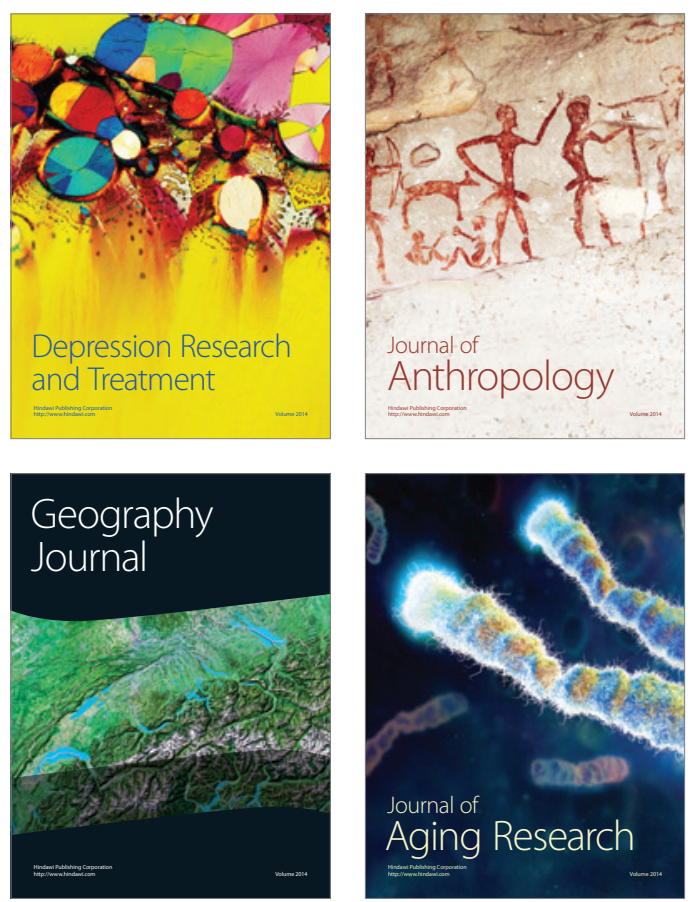
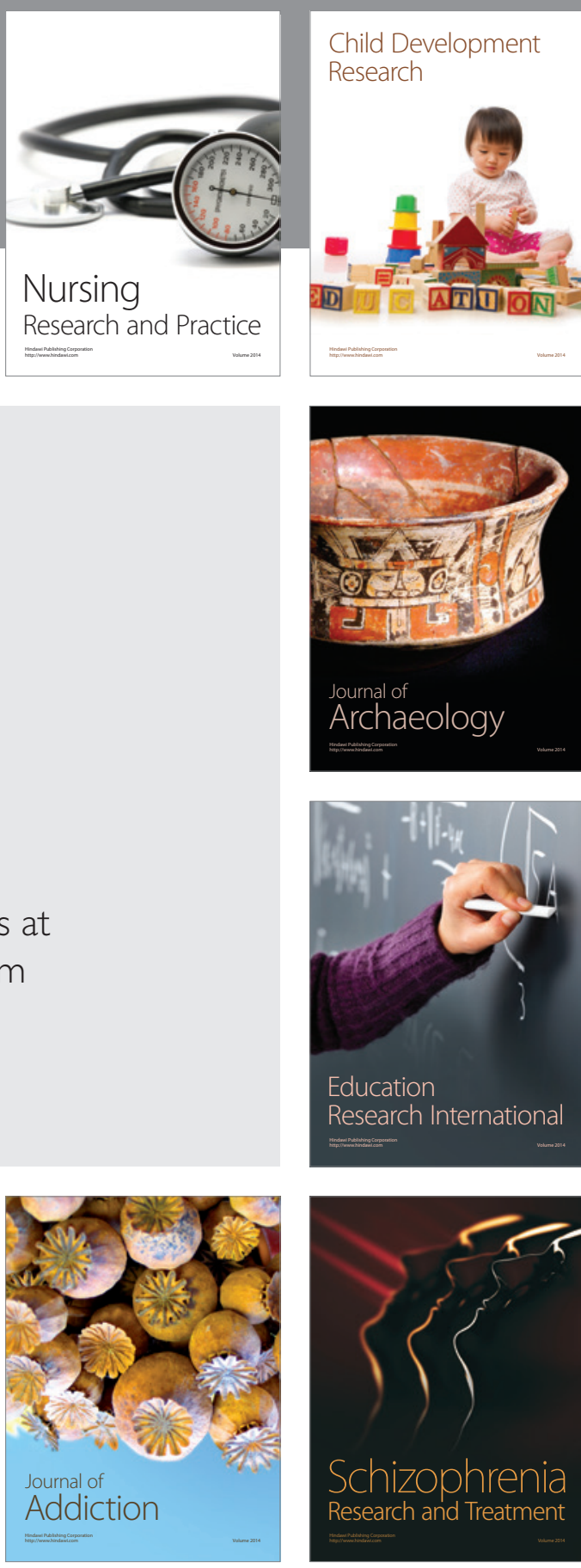

(D)
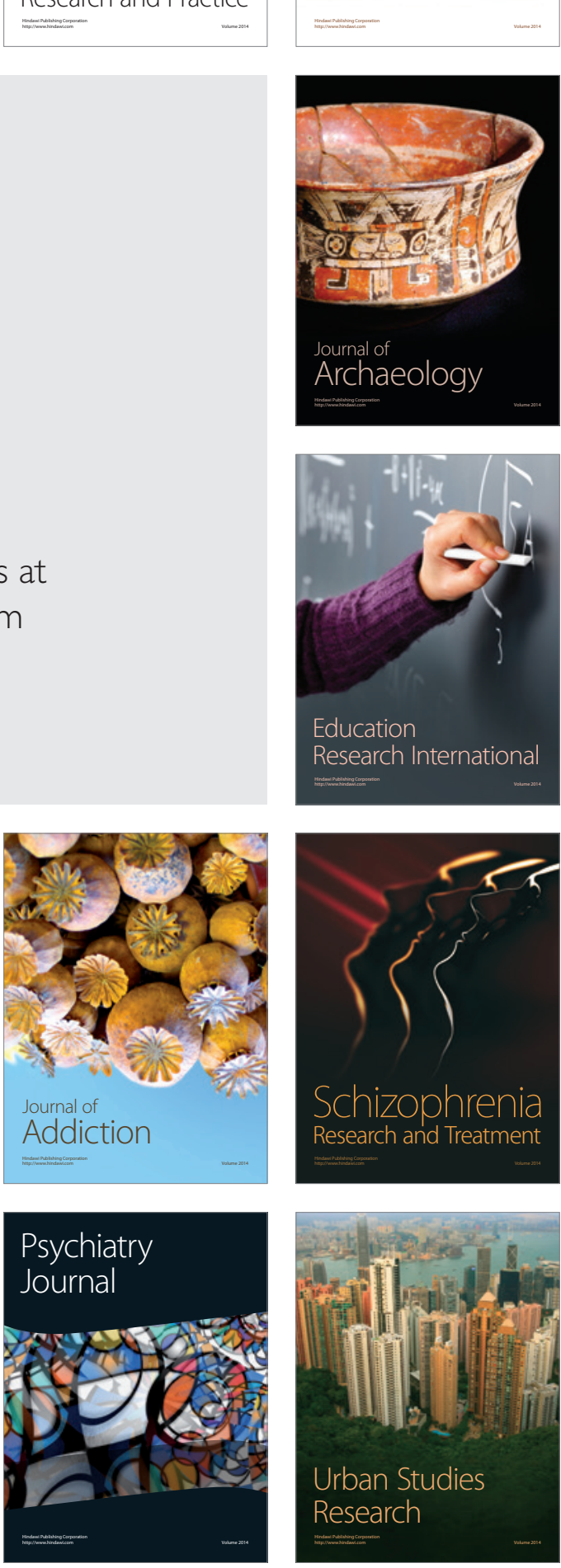